\title{
Respite Care, Marital Quality, and Stress in Parents of Children with Autism Spectrum Disorders
}

Amber Harper

Giant Steps - Wasatch Mental Health, amber.harper@gmail.com

Tina Taylor

Brigham Young University, tina_taylor@byu.edu

James Harper

Brigham Young University - Provo, james_harper@byu.edu

Susanne Olsen Roper

Brigham Young University - Provo

Mikle South

Brigham Young University - Provo, south@byu.edu

Follow this and additional works at: https://scholarsarchive.byu.edu/facpub

Part of the Counseling Psychology Commons

\section{Original Publication Citation}

Respite care, marital quality, and stress in parents of children with autism spectrum disorders. Journal of Autism and Developmental Disorders. doi: 10.1007/s10803-013-1812-0

\section{BYU ScholarsArchive Citation}

Harper, Amber; Taylor, Tina; Harper, James; Roper, Susanne Olsen; and South, Mikle, "Respite Care, Marital Quality, and Stress in Parents of Children with Autism Spectrum Disorders" (2013). Faculty Publications. 1497.

https://scholarsarchive.byu.edu/facpub/1497

This Peer-Reviewed Article is brought to you for free and open access by BYU ScholarsArchive. It has been accepted for inclusion in Faculty Publications by an authorized administrator of BYU ScholarsArchive. For more information, please contact ellen_amatangelo@byu.edu. 
Respite Care, Marital Quality, and Stress in Parents of Children with Autism Spectrum Disorders

\author{
Amber Harper $a$ \\ Tina Taylor Dyches, EdD $\mathrm{b}$ \\ James Harper, $\mathrm{PhD}_{\mathrm{c}}$ \\ Susanne Olsen Roper, $\mathrm{PhD}_{\mathrm{d}}$ \\ Mikle South, $\mathrm{PhD}_{\mathrm{e}}$ \\ aGiant Steps - Wasatch Mental Health \\ 921 North 1240 East \\ Orem, Utah 84097, USA \\ (801) 226-5437 \\ aharper@wasatch.org \\ ${ }_{\mathrm{b}}$ Department of Counseling Psychology and Special Education \\ 340-F McKay Building \\ Brigham Young University \\ Provo, UT 84602, USA \\ (801) 422-5045 \\ Fax: (801) 422-0198 \\ Tina_dyches@byu.edu \\ cSchool of Family Life \\ 273 Taylor Building \\ Brigham Young University \\ Provo, UT 84602, USA \\ (801) 422-3888 \\ james_harper@byu.edu \\ ${ }_{\mathrm{d}}$ School of Family Life \\ 2089 Joseph F. Smith Building \\ Brigham Young University \\ Provo, UT 84602, USA \\ 801-422-2058 \\ Susanne_olsen_roper@byu.edu \\ eDepartment of Psychology and Neuroscience Center \\ 245 Taylor Building \\ Brigham Young University \\ Provo, Utah 84602, USA \\ (801) 422-4058 \\ south@byu.edu
}

Citation: Harper, A., Dyches, T. T., Harper, J., Roper, S. O., \& South, M. (2013). Respite care, marital quality, and stress in parents of children with autism spectrum disorders. Journal of Autism and Developmental Disorders. doi: 10.1007/s10803-013-1812-0

The final publication is available at http://link.springer.com/article/10.1007/s10803-013-1812-0 
Running Head: RESPITE CARE, MARITAL QUALITY, AND STRESS

\begin{abstract}
Parents of children with autism spectrum disorders (ASD) are at risk for having higher stress and lower marital quality than other parents. Survey data regarding respite care, marital quality, and daily hassles and uplifts were obtained from 101 mother-father dyads who were together raising at least one child with ASD (total \# of children =118). Number of hours of respite care was positively related to improved marital quality for both husbands and wives, such that a one-hour increase in weekly respite care was associated with a one-half standard deviation increase in marital quality. This relationship was significantly mediated by perceived daily stresses and uplifts in both husbands and wives. More respite care was associated with increased uplifts and reduced stress; increased uplifts were associated with improved marital quality; and more stress was associated with reduced marital quality. The number of children in the family was associated with greater stress, and reduced relational quality and daily uplifts. Results suggest policymakers and practitioners should develop supports for providing respite for families raising children with ASD.
\end{abstract}

Keywords: Autism spectrum disorders; marital quality; respite; social support; stress; mothers and fathers 
Running Head: RESPITE CARE, MARITAL QUALITY, AND STRESS

Respite Care, Marital Quality, and Stress in Parents of Children with Autism Spectrum Disorders

Parenting in general can be stressful, but parenting children with autism spectrum disorders (ASD) can be particularly difficult and burdensome. Existing research regarding adaptation of parents raising children with ASD has shown elevated stress levels in both mothers and fathers (Brobst, Clopton, \& Hendrick, 2009; Davis \& Carter, 2008; Rao \& Beidel, 2009). Common sources of stress in parents of children with ASD include inappropriate and unpredictable behavior of the child, concerns about the future, and education of the child (Osborne \& Reed, 2010; Tehee, Honan, \& Hevey, 2009). Parents of children with ASD report that they are "stressed out,” "exhausted," "burned out” and at their "wits end” due to caregiving 24 hours a day, 365 days a year (Doig, McLennan, \& Urichuk, 2009).

Parenting a child with ASD has been reported to be more difficult than parenting a child with a different type of disability such as Down syndrome, ADD/ADHD, or parenting a child with no disability (Brobst et al., 2009; Dabrowska, \& Pisula, 2010; Hayes \& Watson, 2013; Lee, Harrington, Louie, \& Newschaffer, 2008; Meadan, Halle, \& Ebata, 2010). The unique stressors associated with the child's impaired communication, inappropriate social engagement, and challenging behavior appear to significantly impact parents’ adaptive functioning. Based upon data from a national survey of children's health, parents of children with ASD have more caregiving burden, more limits on family and community activities, and are more likely to quit their jobs due to childcare problems than parents of children with ADD/ADHD or parents of children who do not have disabilities (Lee et al., 2008). A study of 162 parents of children with autism, Down syndrome, and children without disabilities indicates that on almost every variable studied, the parents of children with autism had increased burden than the other two groups (e.g., stress, dependency and management, limits of family opportunities, life span care, family 
Running Head: RESPITE CARE, MARITAL QUALITY, AND STRESS

disharmony, preference for institutional care, and personal burden; Dabrowska \& Pisula, 2010).

In addition to stressors associated directly with the child with ASD, parents report difficulties in family and marital quality. Such families have lower family cohesion, family adaptability, affection expression, and marital satisfaction than do families whose children do not have disabilities (Brobst et al., 2009; Gau, Chou, Chiang, Lee, Wong, Chou, \& Wu, 2011; Higgins, Bailey, \& Pearce, 2005; Parker, Mandleco, Roper, Freeborn, \& Dyches, 2011). The negative impact of raising a child with ASD appears to be greater for mothers than for fathers, as noted in research of 151 families of children with autism (Gau et al., 2011). A study of 391 parents of children with ASD indicates marital difficulties continue to be present when the child with autism reaches adolescence and early adulthood (Hartley, Barker, Seltzer, Floyd, Greenberg, Orsmond, \& Bolt, 2010).

Poor marital quality in parents of children with ASD has led many to erroneously cite an 80\% divorce rate for these families (Freedman, Kalb, Zablotsky, \& Stuart, 2012). Yet no empirical studies have validated this finding. One study of 391 parents of children with ASD in two U.S. states has shown a greater likelihood for divorce than other parents, with a $23.5 \%$ rate compared to 13.8\% (Hartley et al., 2010). However, a United States population-based, crosssectional survey of 77,911 parents revealed "no evidence to suggest that children with ASD are at an increased risk for living in a household not comprised of their two biological or adoptive parents” (Freedman et al., 2012, p. 545). But viewing stress and marital discord alone represents only two of many facets of complex family functioning (McCubbin \& Patterson, 1983). 


\section{Running Head: RESPITE CARE, MARITAL QUALITY, AND STRESS}

\section{Respite Care as Potential Support}

Three primary types of resources are available to families facing various stressors: personal resources of each family member (e.g., physical and emotional health, financial wellbeing); internal resources of the family system (e.g., cohesion, adaptability, communication, mutual support); and external social support (e.g., respite care). While decades of research have focused on the role of stressors in the lives of families raising children with ASD, relatively little research has focused on external social support. Respite care is an example of an external resource designed to give parents a “short break” from someone who has significant care requirements. Respite care gives family a chance to "'rest', 'refresh', 'relax', 'refocus', 'regroup' and 'recharge’” (Doig et al., 2009, p. 236). It shifts the focus from the child's needs to the family members' needs, so parents have time to do more typical activities (e.g., go grocery shopping, eat out at a restaurant, clean the house) and to spend time with their spouse and other children without being continually focused on the child who requires vigilant care (Doig et al., 2009).

Provision of respite care is based on the characteristics of the individual who requires care (e.g., severe functional limitations, challenging behaviors) and characteristics of the family, such as high stress, low levels of informal support, and financial strains (Nankervis, Rosewarne, \& Vassos, 2011). A number of individuals can provide care (e.g., trained professionals, private providers, extended family members, volunteers), in various settings (e.g., family home, community or residential setting), for various periods of time (e.g., few hours to several days or longer, if necessary), and at various times (e.g., evenings, weekends, overnight). Care can be funded through personal resources or through private or government agencies (Robertson et al., 2011). 
Running Head: RESPITE CARE, MARITAL QUALITY, AND STRESS

Respite care has been shown to reduce caregivers’ stress, enable caregivers to complete daily tasks, facilitate the long-term caregiving in the home, provide parents with time to spend with their other children, and help families to live "a more ordinary life” (Robertson et al., 2011, p. 369). A study of 148 families indicates the provision of respite care is associated with lower rates of foster care placement and maltreatment of children with developmental disabilities, including autism (Cowan \& Reed, 2002). Benefits to siblings and children have also been reported (Langer et al., 2010; Welch et al., 2012). Although respite care is a positive option that might decrease parents’ stress levels and increase marital quality, very few empirical studies have examined the relationship between respite care and marital relationships. A couple of older qualitative studies have reported a benefit of respite care on marriage (Stalker, 1988; Stalker \& Robinson, 1994), and one study reported no significant differences in a small sample of couples who received respite care $(n=48)$ and those who did not $(n=18)$ (Bose, 1991). Furthermore, few studies have examined how respite care is related to marital processes in families raising a child with ASD, and most research neglects the perceptions and experiences of fathers (Robertson et al., 2011). In addition, no studies have considered how resources in the form of daily uplifts—positive factors to balance out the negative daily hassles—-may be related to quality of marriage. Furthermore, studies need to be conducted to determine if respite care is directly related to marital quality.

Rather than viewing the child with ASD as a source of stress and family members’ functioning levels as an outcome, as is typical in many studies, the research reported here was designed to more systemically conceptualize the relationships among multiple variables of family functioning (Hastings et al., 2005). The purpose of this study was twofold: (a) to examine the relationship between respite care and quality of marriage for couples with a child with ASD, 


\section{Running Head: RESPITE CARE, MARITAL QUALITY, AND STRESS}

with wife and husband stress as potential mediating variables, and (b) to examine maternal and paternal daily uplifts as potential mediating variables. Based on trends from the current literature, we expected to find the following:

1. We predicted that level of respite care would be positively associated with perceived marital quality in both husbands and wives.

2. We likewise predicted that level of respite care would be positively related to parentreported uplifts and negatively correlated with parent-reported stresses in both husbands and wives.

3. We predicted that marital quality would be negatively correlated with daily stresses and positively correlated with daily uplifts in both husbands and wives.

4. We predicted that partner effects from wife daily stress would be negatively related to husband relationship quality and that husband daily stress would be negatively related to wife relationship quality, even when controlling for the relevant actor effects. Likewise we predicted that wife daily uplifts would be positively related to husband marital quality and that husband daily uplifts would be positively related to wife marital quality.

5. Finally, we predicted that the relationship between respite care and marital quality would be significantly mediated by daily stresses and uplifts.

\section{Methods}

\section{Participants and Settings}

Participants included 101 mother/father heterosexual dyads of children with ASD who completed the questionnaires either via a web link $(n=89)$ or on paper $(n=12)$. They were recruited through letters to local schools and programs for students with ASD, autism-specific 
Running Head: RESPITE CARE, MARITAL QUALITY, AND STRESS

email list serves, Facebook postings, and national autism community websites such as Autism Speaks. Each partner in the couple was instructed to complete the questionnaire independently. Inclusion criteria included that (a) the parents had a child with ASD as evidenced by either an IEP classification or a medical diagnosis, and (b) the parents were married to each other. Both partners from 101 different couples completed the questionnaire. The average age of husbands was 39.21 years $(S D=6.89)$, and the average age of wives was 38.01 years $(S D=7.04)$. The average length of marriage for the couples was 11.89 years $(S D=3.12)$, and the average number of children was $3.09(S D=1.65)$. Mothers were available to be the primary caregivers of the children in the household, with husbands working an average of 41.27 hours $(S D=12.17)$ and only 4\% were unemployed, and mothers worked an average of 12.17 hours per week $(S D=.70)$, and $71.3 \%$ were unemployed. Husbands reported an annual household income of \$55,353 (SD = $\$ 18,649)$, and wives reported $\$ 55,349(S D=\$ 18,713)$. Approximately $97 \%$ of the couples were both biological parents of the child diagnosed with ASD, and approximately 3\% were remarried with one of the parents being the biological parent. Most of the participants were White (husbands 82.2\%, wives 86.1\%); others were Hispanic or Latino (husbands 8.9\%, wives 6.9\%), African American (husbands 5\%, wives 4\%), Native Hawaiian/Pacific Islander (husbands .9\%, wives $0 \%$ ), or of another race (husbands $3 \%$, wives $3 \%$ ). The majority of the participants were from the Rocky Mountain area (53.1\%), with 14.9\% from the South, 11\% from the West Coast, 6.6\% from the Southwest, 5.6\% from the Northeast, $4.4 \%$ from the Mid-Atlantic, and $4.4 \%$ from the Midwest. Many of the participants had advanced degrees, with $43.5 \%$ of husbands and $43.9 \%$ of wives holding bachelor's degrees, $12.5 \%$ of husbands and $8.8 \%$ of wives holding master's degrees, and $5.1 \%$ of husbands and $4.1 \%$ of wives holding doctorate/professional degrees. Participants who had completed some college included $26.5 \%$ of husbands and $32.4 \%$ 
Running Head: RESPITE CARE, MARITAL QUALITY, AND STRESS

of wives, while $13.4 \%$ of husbands and $10.8 \%$ of wives were high school graduates. No participants had less than a high school education.

\section{Measures}

\section{Parent Variables}

Two scales were used to characterize marriage quality. The Revised Dyadic Adjustment Scale (RDAS; Busby, Christensen, Crane, \& Larson, 1995) is a 14-item questionnaire used to measure marital adjustment using a 6-point Likert scale ranging from 0 (always disagree) to 5 (always agree) regarding questions such as "How often do you and your mate engage in outside interests together?”; "Please indicate the extent of agreement between you and your partner on making major decisions"; and “Do you ever regret that you married?” The answers to the 14 items on the three subscales are summed, yielding a score that can range from 0 to 70 , with 48 being the cut-off score for discriminating distressed from non-distressed couples (Busby et al., 1995). Higher scores indicate higher perceived marital quality. The RDAS has demonstrated adequate reliability and validity, and loadings for the stated factors range from .74 to .97.

The Revised Experiences in Close Relationships Questionnaire (RECRQ; Fraley, Walker, \& Brennan, 2000) measures the degree of attachment in a romantic relationship. It is comprised of two subscales, measuring anxiety and avoidance, both with 18 items based on a 7point Likert scale ranging from 1 (strongly disagree) to 7 (strongly agree). Examples from the Anxious Attachment subscale include "I am afraid I will lose my partner’s love” and “I often worry that my partner does not really love me.” Examples from the Avoidant Attachment subscale include "I find it difficult to allow myself to depend on my partner" and "I prefer not to show my partner how I feel deep down.” Answers to the 18 items on each subscale are summed, and total scores can range from 18 to 126. Reported reliability coefficients are above .90 (Fraley 
Running Head: RESPITE CARE, MARITAL QUALITY, AND STRESS

et al., 2000), and convergent validity with the Adult Attachment Interview (Main \& Cassidy, 1988 ) is .64 for the attachment and .68 for the avoidance sections.

Two latent variables for marital quality were created, one for the husband and one for the wife, with the RDAS total score and the Anxious and Avoidant Attachment scales from the RECRQ as indicators.

\section{Daily Hassles and Uplifts}

Latent variables regarding stresses and uplifts were created from the Hassles and Uplifts Scale (HUS; Lazarus \& Folkman, 1984). The HUS includes 53 descriptions of daily events related to work, money, and extended family. Participants indicate how much of a daily hassle and how much of a daily uplift they experience from each item, using a Likert scale from 0 (not at all) to 4 (extreme). Item frequency is calculated by counting the number of items that have a score greater than zero (range 0-53), while the intensity scale is calculated by summing the scores of all items (range 0-212). The HUS has been found to correlate with both illness and distress, with good test-retest reliability for both hassles and uplifts (Touliatos, Perlmutter, \& Straus; 1990). The stress and uplifts latent variables each included two indicators, frequency and intensity, and were calculated separately for husbands and wives.

\section{Respite Care}

Respite care was measured with two questions. The first question asked respondents to indicate how much respite care they were receiving in hours and minutes from Monday through Friday in a typical week. Respite care was defined as "planned care for the child with autism to provide relief to the permanent caregiver.” The second question asked how much respite care they were receiving on typical weekend days, Saturday and Sunday. The answers to these two questions were summed to create a total number of hours for respite care. If more than one child 
Running Head: RESPITE CARE, MARITAL QUALITY, AND STRESS

with ASD in the family was receiving respite care, the researchers added the hours for the second or third child unless the parent reported that the respite hours occurred at the same time as the reported hours for the first child. In other words, we did not double count hours if two or more children were receiving respite care during the same exact hours. Since both husbands and wives responded to this question, their respective sums of hours and minutes of respite care were the two indicators for the latent variable number of hours of respite care.

\section{Demographic Questionnaire}

The demographic questionnaire included questions about parents’ ages, length of marriage, annual household income, hours of employment, education level, and race; also about the number of children, their ages, and genders; along with the medical diagnoses of the child/or children with ASD. These variables were used as control variables in the analysis. One question about their satisfaction with their respite care provider was also included.

\section{Research Design}

This study was a multivariate correlational design using AMOS 16 (SPSS, 2009) to perform structural equation modeling. An Actor Partner Independence Model (APIM; Kenny, Kashy, \& Cook, 2006) was used to estimate the effects of the independent variable (amount of respite care) on the dependent variables (husband and wife relational quality). The indirect paths through husband and wife daily stress were also estimated. The APIM included the actor effects, or the paths between the same person's variables (e.g., number of hours of respite care to husband's relational quality as well as through husband's daily stress). The same relationships were examined for the wife. The partner effects were the influences of each partner's variables on his or her spouse (e.g., number of hours of respite care predicting husband's relational quality filtered through the wife's daily stress, and the partner paths for the husband's daily stress to the 
Running Head: RESPITE CARE, MARITAL QUALITY, AND STRESS

wife's relationship quality). A second APIM model was also created in which husband daily uplifts and wife daily uplifts were substituted for husband stress and wife stress as potential mediating variables.

As can be seen in Figure 1, the error terms for the mediating variables as well as husband's and wife's latent relationship quality were correlated since both partners were reporting on their marriage.

$<$ Insert Figure 1 here $>$

\section{Statistical Analysis}

The first step in the analysis was to examine descriptive statistics. Means, standard deviations, and correlations between all variables were calculated. In the next step, confirmatory factor analysis was used to determine factor loadings for indicators on each latent variable for both the model with stress as the mediator and the second model with uplifts as the mediator. Factor loadings for the measures of latent variables ranged from -.81 to .99 (see Figures 2 and 3). Then unstandardized and standardized beta coefficients were calculated to determine the strength of the direct and indirect paths in both structural models, one with husband stress and wife stress as mediating variables and one with husband uplifts and wife uplifts as potential mediating variables. Sobel tests were calculated to determine if the mediation effects were statistically significant.

\section{Results}

The study included 118 children (42 females, 76 males) from 101 families. Ages of the children with ASD ranged from 1 to 33 years $(\bar{x}=8.23$; $S D=3.54)$. Parents self-reported the child's diagnostic classifications, as shown in Table 1. Because this was a web-based questionnaire study we did not obtain any additional confirmation of diagnosis. Parents reported 
Running Head: RESPITE CARE, MARITAL QUALITY, AND STRESS

that $63.6 \%$ of the children received some type of respite care. Of the types of respite care, $28.0 \%$ was provided by grandparents, $26.7 \%$ was provided by a babysitter, $21.3 \%$ was provided by a community agency, $16.0 \%$ was provided by extended family, and $8.0 \%$ was provided by a combination of the above. Of those parents receiving respite care, 88.6\% reported being satisfied with their care provider.

$<$ Insert Table 1 here $>$

Correlational Data

Table 2 shows means, standard deviations, and correlations for key variables including respite quantity; stress, hassles and uplifts; and relationship quality. These were all correlated in the expected directions. In this section we highlight the correlations between respite care and marital distress. Distressed marriages, as determined by Revised Dyadic Adjustment Scale (RDAS) cut-off scores below 48 (Busby et al., 1995), were reported by $14.8 \%$ of husbands and $16.7 \%$ of wives. Independent t-tests showed that RDAS mean scores from this sample were not significantly different than those of a sample of 581 patients with coronary artery disease (Kazemi-Saleh, Pishgou, Farrokhi, Assari, Fotros, \& Naseri, 2008). Table 2 shows that the amount of respite care was significantly related to marital quality, including significant positive correlations with RDAS total scores for both husbands and significant negative correlations with the RECRQ for both anxious and avoidant attachment, for both husbands and wives.

$<$ Insert Table 2 here $>$

\section{Structural Model Results}

In terms of determining appropriateness of using Structural Equation Modeling (SEM) for a sample size of 202 (101 husbands and 101 wives) Kline (2011) recommends the ratio of cases $(\mathrm{N})$ to substantive parameters $(\mathrm{q})$ be at least 10:1; however, a simulation study performed 
Running Head: RESPITE CARE, MARITAL QUALITY, AND STRESS

by Nevitt and Hancock (2004) found that even with non-normal data, test statistics still performed adequately with samples between 50 and 100 cases.

Figure 2 shows the factor loadings for each measured variable on their respective latent variables, as well as the standardized and unstandardized beta coefficients for each structural path in the model with husband and wife stress as potential mediators. The overall fit indices showed that the hypothesized model was a good fit to the actual data. The chi square was insignificant $\left(X^{2}=36.51, d f=35, p=.40\right)$; the Comparative Fit Index (CFI) was well above .95 (CFI=.996); the Root Mean Square Error of Approximation (RMSEA) was less than .05 (RMSEA=.015); and the Standardized Root Mean Square Residual (RMSR) was less than .08 (RMSR=.030). The overall $\mathrm{R}^{2}$ for wives’ marital quality was .59 and for husbands' marital quality was .57 , meaning that the overall model explained $59 \%$ of the variance for wives' marital quality and 57\% of the variance for husbands’ marital quality.

$<$ Insert Figure 2 here $>$

Hypothesis 1 stated that there would be a significant positive relationship between number of hours of respite care and relationship quality. This was confirmed for both husbands $(\beta=.42, \mathrm{p}<.001)$ and wives $(\beta=.56, \mathrm{p}<.001)$. Unstandardized beta values indicated that for every additional hour of respite care per week, wives’ relationship quality increased 3.79 and husbands’ relationship quality increased 6.14 units.

Figure 3 shows the results for the model with husband and wife uplifts as potential mediators. As was true for the first model, the overall fit showed that the data had good fit with the hypothesized model $\left(X^{2}=35.30, d f=37, p=.55\right)$, with a $C F I=.997, R M S E A$ of .001 and an SMSR of .028. The overall $\mathrm{R}^{2}$ for this second model was .51 for wives and .57 for husbands. $<$ Insert Figure 3 here $>$ 


\section{Running Head: RESPITE CARE, MARITAL QUALITY, AND STRESS}

Hypothesis 2 stated that that the number of hours of respite care would be positively related to parent-reported uplifts and negatively related to parent-reported stresses. This was also confirmed for wives $(\beta=.20, p<.01$ for uplifts; $\beta=-.33, \mathrm{p}<.001$ for stress $)$ and for husbands ( $\beta=.37, p<.001$ for uplifts; $\beta=-.30, p<.001$ for stress). Unstandardized betas indicate that for every hour of respite care, daily stress decreased by approximately 5 units for wives and almost 6 units for husbands. Every hour of additional respite care increased husband uplifts by more than 5 units while wives uplifts increased by just more than 2 units.

Hypothesis 3 further predicted that marital quality would be negatively related to daily stress and positively related to daily uplifts. As shown in Figures 2 and 3, this was also confirmed for both wives $(\beta=-.37, \mathrm{p}<.001$ for stress; $\beta=.34, \mathrm{p}<.001$ for uplifts $)$ and husbands $(\beta=-$ $.17, \mathrm{p}<.05$ for stress; $\beta=.47, \mathrm{p}<.001$ for uplifts). For every unit of increase in daily stress, wife relationship quality decreased by 1.05 units and husband relationship quality decreased by .81 units.

Hypothesis 4 was related to "partner effects"; that is, how one person's daily stress or uplifts related to the partner's report of relationship quality. Wife daily stress was negatively related to husband relationship quality $(\beta=-.18, p<.05)$, but husband daily stress was not significantly related to wife relationship quality $(\beta=-.12)$. Wife daily uplifts was positively related to husband relationship quality $(\beta=.28, p<.001)$, and husband daily uplifts was positively associated with wife relationship quality $(\beta=.38, p<.001)$.

As shown in Figure 2, the only control variable that was a significant predictor was number of children which was positively related to wife daily stress $(\beta=.29, p<.001)$, and negatively related to relationship quality for both wives $(\beta=-.21, p<.01)$ and husbands $(\beta=-.31$, $p<.001$ ). As shown in Figure 3, number of children was negatively related to daily uplifts for 
Running Head: RESPITE CARE, MARITAL QUALITY, AND STRESS

both husbands $(\beta=p<-.25, p<.001)$ and wives $(\beta=-.18, p<.05)$, and negatively related to relationship quality for both husbands $(\beta=-.30, p<.001)$ and wives $(\beta=-.24, p<.01)$.

\section{Mediation Results}

Our final hypothesis was that relationships between respite care quantity and relationship quality would be significantly mediated by daily stresses and uplifts. This hypothesis was partially supported by our data. A Sobel Test showed that wife daily stress significantly mediated the relationship between number of hours of respite and wife marital quality (Sobel=8.41, $\mathrm{p}<.001$ ), but wife daily stress was not a significant mediator of the relationship between the number of hours of respite and husband marital quality (Sobel=.38, $\mathrm{p}=.37$ ). Husband daily stress was a significant mediator between number of hours of respite care and husband marital quality (Sobel=5.25, $\mathrm{p}<.001$ ).

Four additional Sobel Tests were performed for each of the mediating paths in the model shown in Figure 3. The actor effects paths were each statistically significant (Sobel=8.84, $\mathrm{p}<.001$ for the path through wife uplifts to her marital quality; Sobel=20.87, $\mathrm{p}<.001$ for the path through husband uplifts to his marital quality). The partner effects paths were likewise significant (Sobel=8.45, $\mathrm{p}<.001$ for the path through wife uplifts to husband marital quality; Sobel=18.90, $\mathrm{p}<.001$ for the path through husband uplifts to wife marital quality).

\section{Discussion}

We hypothesized a strong positive relationship between respite care and marriage quality in couples raising a child diagnosed with an autism spectrum disorder. We further hypothesized that daily stresses and uplifts experienced by parents would mediate this relationship. These hypotheses were supported by online survey data collected from 101 mother/father dyads who were raising a total of 118 children with ASD. Figure 4 provides a summary of this overall 
model.

\section{$<$ Insert Figure 4 here $>$ \\ Respite Care and Marital Quality}

Marital quality is an important factor in the well-being of parents of children with developmental disabilities, contributing to lower rates of depression and parenting-related stress, as well as greater parenting efficacy (Kersh, Hedvat, Hauser-Cram, \& Warfield, 2006). Previous research has suggested that couples raising a child with ASD have been reported to have lower marital happiness than other couples (Higgins et al., 2005). The current study found similar levels of distressed relationships in a sample of parents raising a child with ASD compared to a large sample of medical patients (as reported by Kazemi-Saleh et al., 2008), with approximately $16 \%$ of couples reporting distress in their marital relationships. While there are several marital processes which we did not investigate in this study that might be significantly related to the outcome variables, results confirm that support factors outside of the immediate family system significantly predict marital quality, with the number of hours of respite care being related to marital quality for both husbands and wives. Particularly impressive was the finding that just one additional hour of respite care per week was related to an increase of 6 to 7 points in marital quality, which is approximately one half of a standard deviation. Thus if a husband or a wife scored 43 on the Revised Dyadic Adjustment Scale, one hour of additional respite care might raise the score by 6 points--moving the couple from the distressed to the non-distressed range. This finding offers hope to couples parenting a child with ASD: one somewhat straightforward way to strengthen their marriage is the use of available respite care.

\section{Respite Care and Stress}

Parents raising children with ASD, particularly mothers, have been reported to 
Running Head: RESPITE CARE, MARITAL QUALITY, AND STRESS

experience high degrees of stress and severe inadequacies in support and respite care (Dillenburger, \& McKerr, 2011; Hastings et al., 2005; Estes, Munson, Dawson, Koehler, Zhou, \& Abbott, 2009; Sawyer, Bittman, La Greca, Crettenden, Harchak, \& Martin, 2010). Limited empirical research supports the benefits of respite care on aspects of parental well-being such as anxiety and stress in families raising children of various ages with ASD (Barker, Hartley, Seltzer, Floyd, Greenberg, \& Orsmond, 2011; Dillenberger \& McKerr, 2011); however, respite care may be one of the strongest stress relievers for families (Ruble \& McGrew, 2007; Tehee et al., 2009). The findings of the present study confirm the benefits of respite care for reducing perceived stress in both wives and husbands. Previous findings in research on parents of children with ASD have been inconsistent on whether mothers experience more stress than fathers (see Hastings et al., 2005; Tehee et al., 2009). Our findings that mothers and fathers reported similar stress levels may be related to the fact that stress was measured by daily hassles rather than by specific parenting stressors.

\section{Respite Care and Daily Uplifts}

A unique contribution of the current study is the finding that number of hours of respite care is also positively associated with uplifts, especially for fathers. Additionally, both wives and husbands seem to label many people and events as both stressors and uplifts, with wives endorsing $62 \%$ of items and husbands endorsing $58 \%$ of items as both a stressor and an uplift. For example, $88 \%$ of wives and $82 \%$ of husbands felt that their children with ASD were in both categories. Finding positive meaning in the midst of such difficult parenting conditions is essential for good mental health (Myers, Mackintosh, \& Goin-Kochel, 2009).

\section{Mediating Role of Daily Uplifts and Stress on Marital Quality}

Similar to research from Lickenbrock, Ekas, and Whitman (2011) which found that 
Running Head: RESPITE CARE, MARITAL QUALITY, AND STRESS

mothers who perceived their child in positive terms had adaptive marital adjustment and wellbeing, our results show significant relationships between daily uplifts and marital quality for both husbands and wives. Our path models show that husband uplifts was a stronger mediator than wife uplifts in the relationship between hours of respite care and both husband and wife marital quality. But wife stress was a stronger mediator between hours of respite and wife and husband marital quality. Stated simply, maintaining higher levels of positive perceptions by husbands and reducing levels of perceived stress in wives positively impacted marital quality in relation to the number of hours of respite care provided.

The finding that stress and uplifts only partially mediated the relationship between number of hours of respite care and marital quality indicates that other processes may mediate these relationships. Our correlational findings may be related to other variables. For example, it is possible that parents who perceive more uplifts in their lives might be more likely to seek respite care services than other parents. It may be that respite care allows couples to spend time together because they have been temporarily relieved of caregiving responsibilities. Also, parents are likely to have sources of uplifts outside of the context of parenting a child with ASD (Kersh et al., 2006).

Additional factors related to parental stress may include the child's behavior, caregiver burden, financial stress, and social isolation. Respite care gives parents a break from the child who may have challenging behaviors, potentially decreasing the stress of the parents. Problem behavior of children with ASD is related to the stress of parents (Brobst et al., 2009), and these behaviors are more predictive of parental stress than the child's adaptive behavior and severity of autistic symptoms (Hastings et al., 2005). When parents' stress is reduced, parents are likely to cope more effectively with their children's behaviors, leading to more adaptive family 
Running Head: RESPITE CARE, MARITAL QUALITY, AND STRESS

functioning. Parents raising children with ASD also have a high level of caregiver burden (Lee et al., 2008), which, according to the findings of this study, might be alleviated through respite care. Financial stress may be a factor related to couples’ stress, since raising children with ASD is more expensive than raising children without ASD (Liptak, Stuart, \& Auinger, 2006), and often one parent is not in the workforce due to caregiving demands (Baillargeon, Bernier, \& Normand, 2011; Cowan \& Reed, 2002; Dillenburger et al., 2010). Social isolation is another factor that may be related to parental stress, as many parents of children with ASD have reported feeling isolated from their peers and community (Higgins et al., 2005; Nankervis et al., 2011; Rao \& Beidel, 2009). Therefore, support for reducing stress in parents raising a child with ASD is warranted, particularly for mothers, who tend to spend a great deal of time caring for their children as primary caregivers (Benson, Karloff, \& Siperstein, 2008; Cowan \& Reed, 2002; Crowe \& Florez, 2006; Lee et al., 2008; Sawyer et al., 2010) and who may experience mental health problems (Hastings et al., 2005; Sawyer et al., 2010).

\section{Strengths and Limitations}

The strengths of this study include the use of multiple respondents, multiple indicators of the variables, control for measurement error, and the APIM (actor-partner interdependence model) in which husbands and wives actually married to each other were the participants. Many studies of relationships use samples that include separate samples of husbands and wives who are not married to each other. Nonetheless, a significant limitation of this work is that the sample was not selected randomly. Participants were volunteers who responded to targeted invitations and may represent a particularly high level of family functioning. The sample included primarily Caucasian families from the Intermountain West area of the United States and may not generalize to other geographic and cultural norms. Because questionnaires were completed at 
Running Head: RESPITE CARE, MARITAL QUALITY, AND STRESS

participants' homes, we cannot rule out the possibility that parents collaborated in completing the questionnaires, although we asked them not to do so. If some collaboration did occur, the associations between mothers and fathers are likely inflated. Furthermore, we did not specifically ask who served as the primary caregiver of the child with ASD, although many studies of parents of children with disabilities indicate mothers as the primary caretaker (Benson, Karloff, \& Siperstein, 2008; Cowan \& Reed, 2002; Crowe \& Florez, 2006; Gray, 2003; Lee et al., 2008; Sawyer et al., 2010), and 82\% of the fathers in our sample were employed more hours than mothers, and only $1 \%$ of the mothers were employed more hours than the fathers. An additional limitation may be related to self-report bias regarding the number of hours of respite care and the self-reporting of the child's diagnosis.

\section{Implications for Research, Policy, and Practice}

While the current study addresses a call to increase research regarding fathers’ perceptions of respite care (Robertson et al., 2011), several questions remain. One question is whether increasing the number of hours of respite care for couples would actually raise their marital quality. Intervention studies using controlled respite care as the independent variable are necessary to answer this question. Several other questions need to be answered. Is it the quality or quantity of respite care that influences marital quality? What stressors does respite care relieve? Are there differences between couples who spend time together during respite care and those who use the time to complete individual tasks? Does spending time together make a difference in marital quality, or does simply having a break from the child with ASD make a difference?

The findings of this study are relevant for policymakers, practitioners, and families of children with ASD. Policies that encourage broad accessibility of flexible, responsive, and 
Running Head: RESPITE CARE, MARITAL QUALITY, AND STRESS

compassionate respite care are warranted (Oliver \& Mossialos, 2004; Sawyer et al., 2010). Such policies should ensure equality of access to care regardless of the specific diagnosis, age, or behavioral challenges of the child or the socio-economic status, geographic location, or awareness of respite care availability of the family (Doig et al., 2009; Oliver \& Mossialos, 2004). Many parents are unaware of the options available. As one parent stated in a previous study (Dillenberger, Keenan, Doherty, Byrne, \& Gallagher, 2010, p. 18): “If we don’t know the questions to ask [about available services], then we don’t get any answers. Social services should be called secret services.” Targeting widespread media attention to the availability of respite care is recommended.

Implications from these findings are important to professionals who work with families raising a child with ASD. Practitioners need to know the respite care options that are available. Counselors, therapists, psychologists, physicians, school administrators, special education teachers, social workers, and family advocates must be unified in their approach to informing parents and helping them access both formal and informal respite care services. They cannot assume that facilitating access to respite care is the responsibility a separate provider or discipline. A coordinated approach to helping parents obtain and navigate ongoing respite care is long overdue. A model for building social capital by establishing a system of paid and unpaid caregivers is described by Zloty, Roger, and Lobchuk (2011). Options to strengthen networks of caregivers, such as using university students, are described in detail by Openden, Symon, Koegel, and Koegel, (2006) and by Murphy and Verden (2012).

Schools and other agencies that provide parent training or other parental support groups should provide respite care during these meetings (Zloty et al., 2011). As noted by one parent of a child with ASD, “Agencies often set up meetings, training sessions, and workshops for parents, 
Running Head: RESPITE CARE, MARITAL QUALITY, AND STRESS

without offering supportive services like child care, and wonder why parents don't show. Those who cope best will be there; the others will need to be lured” (Sullivan 1979, p. 116).

Respite care needs to be provided by people who can be trusted and trained so families feel comfortable in leaving their child with ASD (Thompson \& Emira, 2011). Professionals could provide training for extended family and community members who are willing to give respite care so they can be confident in how to handle challenging behaviors and to facilitate social skills and effective communication.

\section{Conclusions}

The findings of this study fill a gap in the literature regarding a pervasive and enduring need for families raising children with ASD - respite care. The findings are important to the field because, unlike most research regarding families raising children with ASD, perspectives of both mothers and fathers were assessed. Results indicated that the number of hours of respite care is related to marital quality for both husbands and wives who have a child diagnosed with ASD. Respite care appears to affect marital quality through the individual levels of stress and uplifts of both mothers and fathers. Respite care helps reduce stress, which in turn affects marital quality. Lack of respite care was related to higher stress of both mothers and fathers, and additional hours of respite care was related to higher uplifts of both parents. Policymakers should consider establishing guidelines for providing respite care, as it affects the quality of family life for those who have a child diagnosed with ASD.

For decades parents of children with ASD have yearned for appropriate support to “relieve the family of 'unending front-line fatigue’” (Sullivan, 1979, p. 114) associated with caring for their child with ASD. Respite care, whether provided by family, community members, or governmental agencies, is a critical component in a comprehensive family support 


\section{Running Head: RESPITE CARE, MARITAL QUALITY, AND STRESS}

plan, and even a slight increase in the number of hours of respite care has the potential to improve marital quality. 
Running Head: RESPITE CARE, MARITAL QUALITY, AND STRESS

\section{References}

Baillargeon, R. H., Bernier, J., \& Normand, C. L. (2011). The challenges faced by caregivers of children with impairments of psychological functions: A population-based cross-sectional study. Canadian Journal of Psychiatry, 56, 614-620.

Barker, E. T., Hartley, S. L., Seltzer, M. M., Floyd, F. J., Greenberg, J. S., \& Orsmond, G. I. (2011). Trajectories of emotional well-being in mothers of adolescents and adults with autism. Developmental Psychology, 47, 551-561. doi:10.1037/a0021268

Benson P., Karlof K. L. \& Siperstein G. N. (2008). Maternal involvement in the education of young children with autism spectrum disorders. Autism: The International Journal of Research and Practice 12, 47-63.

Bose, R. (1991). The effect of a family support model on maternal mental health of mothers caring for children with mental handicaps. Research Policy and Planning, 9, 2-8.

Brobst, J. B., Clopton, J. R., \& Hendrick, S. S. (2009). Parenting children with autism spectrum disorders: The couple’s relationship. Focus on Autism Other Developmental Disabilities, 24, 38-49. doi:10.1177/1088357608323699

Busby, D. M., Christensen, C., Crane, D. R., \& Larson, J. H. (1995). A revision of the Dyadic Adjustment Scale for use with distressed and nondistressed couples: Construct hierarchy and multidimensional scales. Journal of Marital and Family Therapy, 21, 289308. doi:10.1111/j.1752-0606.1995.tb00163.x

Cowan, P. S., \& Reed, D. A. (2002). Effects of respite care for children with developmental disabilities: Evaluation of an intervention for at risk families. Public Health Nursing, 19, 272-283.

Crowe, T. K., \& Florez, S. I. (2006). Time use of mothers with school-age children: A 
Running Head: RESPITE CARE, MARITAL QUALITY, AND STRESS

continuing impact of a child's disability. American Journal of Occupational Therapy, 60, 194-203.

Davis, N. O., \& Carter, A. S. (2008). Parenting stress in mothers and fathers of toddlers with autism spectrum disorders: Associations with child characteristics. Journal of Autism and Developmental Disorders, 38, 1278-1291. doi:10.1007/s10803-007-0512-z

Dabrowska, A., \& Pisula, E. (2010). Parenting stress and coping styles in mothers and fathers of pre-school children with autism and Down syndrome. Journal of Intellectual Disability Research, 54, 266-280. doi:10.1111/j.1365-2788.2010.01258.x

Dillenburger, K., Keenan, M., Doherty, A., Byrne, T., \& Gallagher, S. (2010). Living with children diagnosed with autistic spectrum disorder: Parental and professional views. British Journal of Special Education, 37, 13-23. doi:10.1111/j.1467-8578.2010.00455.x

Dillenburger, K., \& McKerr, L. (2011). "How long are we able to go on?" Issues faced by older family caregivers of adults with disabilities. British Journal of Learning Disabilities, 39, 29-38. doi:10.1111/j.1468-3156.2010.00613.x

Doig, J. L., McLennan, J. D., \& Urichuk, L. (2009). 'Jumping through hoops': Parents' experiences with seeking respite care for children with special needs. Child: Care, Health and Development, 35, 234-242. doi:10.1111/j.1365-2214.2008.00922.x

Estes, A., Munson J., Dawson, G., Koehler, E., Zhou, X., \& Abbott, R. (2009). Parenting stress and psychological functioning among mothers of preschool children with autism and developmental delay. Autism, 13, 375-387. doi:10.1177/1362361309105658

Fraley, R. C., Waller, N. G., \& Brennan, K. A. (2000). An item response theory analysis of selfreport measures of adult attachment. Journal of Personality and Social Psychology, 78, 350-365. doi:10.1037//0022-3514.78.2.350 
Running Head: RESPITE CARE, MARITAL QUALITY, AND STRESS

Freedman, B. H., Kalb, L. G., Zablotsky, B., \& Stuart, E. A. (2012). Relationship status among parents of children with autism spectrum disorders: A population-based study. Journal of Autism and Developmental Disorders, 42, 539-548. doi: 10.1007/s10803-011-1269-y

Gau, S. S., Chou, M., Chiang, H., Lee, J., Wong, C., Chou, W., \& Wu, Y. (2011). Parental adjustment, marital relationship, and family function in families of children with autism. Research in Autism Spectrum Disorders, 6, 263-270. doi:10.1016/j.rasd.2011.05.007

Gray, D. E. (2003). Gender and coping: The parents of children with high functioning autism. Social Science and Medicine, 56, 631-642.

Hartley, S. L., Barker, E. T., Seltzer, M. M., Floyd, F., Greenberg, J., Orsmond, G., \& Bolt, D. (2010). The relative risk and timing of divorce in families of children with an autism spectrum disorder. Journal of Family Psychology, 24, 449-457. doi:10.1037/a0019847

Hastings, R. P., Kovshoff, H., Ward, N. J., degli Espinosa, F., Brown, T., \& Remington, B. (2005). Systems analysis of stress and positive perceptions in mothers and fathers of preschool children with autism. Journal of Autism and Developmental Disorders, 35, 635644. doi:10.1007/s10803-005-0007-8

Hayes, S. A., \& Watson, S. L. (2013). The impact of parenting stress: A meta-analysis of studies comparing the experience of parenting stress in parents of children with and without autism spectrum disorder. Journal of Autism and Developmental Disorders, 43, 629-642. doi: 10.1007/s10803-012-1604-y

Higgins, D. J., Bailey S. R., \& Pearce, J. C. (2005). Factors associated with functioning style and coping strategies of families with a child with an autism spectrum disorder. Autism: The International Journal of Research and Practice, 9, 125-137. doi:10.1177/1362361305051403 
Running Head: RESPITE CARE, MARITAL QUALITY, AND STRESS

Kazemi-Saleh, D, Pishgou, B, Farrokhi, F, Assari, S, Fotros, A, \& Naseri, H. (2008). Gender impact on the correlation between sexuality and marital relation quality in patients with coronary artery disease. The Journal of Sexual Medicine, 5, 2100-2106.

Kenny, D. A., Kashy, D. A., \& Cook, W. L. (2006). Dyadic data analysis. New York, NY: Guilford.

Kersh, J., Hedvat, T. T., Hauser-Cram, P., \& Warfield, M. E. (2006). The contribution of marital quality to the well-being of parents of children with developmental disabilities. Journal of Intellectual Disability Research, 50, 883-893. doi:10.1111/j.1365-2788.2006.00906.x

Kline, R. B. (2011). Principles and practice of structural equation modeling (3rd ed.). NY: Guilford.

Langer, S., Collins, M., Welch, V., Wells, E., Hatton, C., Robertson, J., \& Emerson, E. (2010). A report on themes emerging from qualitative research into the impact of short break provision on families with disabled children. Lancaster, UK: Center for Disability Research, Lancaster University.

Lazarus, R. S., \& Folkman, S. (1984). Stress, appraisal, and coping. New York, NY: Springer.

Lee, L. C., Harrington, R. B., Louie, B. B., \& Newschaffer, C. J. (2008). Children with autism: Quality of life and parental concerns. Journal of Autism and Development Disorders, 38, 1147-1160. doi:10.1007/s10803-007-0491-0

Lickenbrock, D. M., Ekas, N. V., \& Whitman, T. L. (2011). Feeling good, feeling bad: Influences of maternal perceptions of the child and marital adjustment on well-being in mothers of children with an autism spectrum disorder. Journal of Autism and Developmental Disorders, 41, 848-858. doi:10.1007/s10803-010-1105-9

Liptak, G. S., Stuart, T., \& Auinger, P. (2006). Health care utilization and expenditures for 
Running Head: RESPITE CARE, MARITAL QUALITY, AND STRESS

children with autism; Data from U.S. national samples. Journal of Autism and Developmental Disorders, 36, 871-879. doi:10.1007/s10803-006-0119-9

Main, M., \& Cassidy, J. (1988). Categories of response to reunion with the parent at age 6: Predictable from infant attachment classifications and stable over a 1-month period. Developmental Psychology, 24, 415-426. doi:10.1037//0012-1649.24.3.415

McCubbin, H. I., \& Patterson, J. M. (1983). The family stress process: The double ABCX model of adjustment and adaptation. Marriage and Family Review, 6, 7-37. doi:10.1300/J002v06n01_02

Meadan, H., Halle, J. W., \& Ebata, A. T. (2010). Families with children who have autism spectrum disorders: Stress and support. Exceptional Children, 77, 7-36.

Murphy, C. M., \& Verden, C. E. (2012). Supporting families of individuals with autism spectrum disorders: Developing a university-based respite care program. Journal of Positive Behavior Interventions. doi:10.1177/1098300712436845. Retrieved from http://pbi.sagepub.com/cgi/content/abstract/1098300712436845v1

Myers, B. J., Mackintosh, V. H. \& Goin-Kochel, R. P. (2009). "My greatest joy and my greatest heart ache:" Parents' own words on how having a child in the autism spectrum has affected their lives and their families' lives. Research in Autism Spectrum Disorders, 3, 670-684. doi:10.1016/j.rasd.2009.01.004

Nankervis, K., Rosewarne, A, \& Vassos, M. (2011). Why do families relinquish care? An investigation of the factors that lead to relinquishment into out-of-home respite care. Journal of Intellectual Disability Research, 55, 422-433. doi:10.1111/j.13652788.2011.01389.x

Nevitt, J., \& Hancock, G. R. (2004). Evaluating small sample approaches for model test statistics 
Running Head: RESPITE CARE, MARITAL QUALITY, AND STRESS

in structural equation modeling. Multivariate Behavioral Research, 39, 439-478. doi:10.1207/S15327906MBR3903_3

Oliver, A. \& Mossialos, E. (2004). Equity of access to health care: Outlining the foundations for action. Journal of Epidemiology and Community Health, 58, 655-658. doi:10.1136/jech.2003.017731

Openden, D., Symon, J. B., Koegel, L. K., \& Koegel, R. L. (2006). Developing a student respite provider system for children with autism. Journal of Positive Behavior Interventions, 8, 119-123. doi:10.1177/10983007060080020301

Osborne, L. A., \& Reed, P. (2010). Stress and self-perceived parenting behaviors of parents of children with autistic spectrum conditions. Research in Autism Spectrum Disorders, 4, 405-414. doi:10.1016/j.rasd.2009.10.011

Parker, J., Mandleco, B., Roper, S. O., Freeborn, D., \& Dyches, T. T. (2011). Religiosity, spirituality, and marital relationships of parents raising a typically developing child or a child with a disability. Journal of Family Nursing, 17, 82-104.

doi:10.1177/1074840710394856

Rao, P., \& Beidel, D. (2009). The impact of children with high functioning autism on parental stress, sibling adjustment, and family functioning. Behavior Modification, 33, 437451. doi:10.1177/0145445509336427

Robertson, J., Hatton, C., Wells, E., Collins, M., Langer, S., Welch, V., \& Emerson, E. (2011). The impacts of short break provision on families with a disabled child: An international literature review. Health and Social Care in the Community, 19, 337-371. doi:10.1111/j.1365-2524.2010.00977.x

Ruble, L. A., \& McGrew, J. H. (2007). Community services outcomes for families and children 
Running Head: RESPITE CARE, MARITAL QUALITY, AND STRESS

with autism spectrum disorders. Research in Autism Spectrum Disorders, 1, 360372. doi:10.1016/j.rasd.2007.01.002

Sawyer, M. G., Bittman, M., La Greca, A. M., Crettenden, A. D., Harchak, T. F., \& Martin, J. (2010). Time demands of caring for children with autism: What are the implications for maternal mental health? Journal of Autism and Developmental Disorders, 40, 620628. doi:10.1007/s10803-009-0912-3

SPSS Inc. (2009). PASW Statistics 18. New York, NY: Prentice Hall.

Stalker, K. (1988). Family-based respite care for children with severe learning difficulties: An evaluation of the Lothian scheme. Social Services Research 1, 1-10.

Stalker, K., \& Robinson, C. (1994). Parents’ views of different respite care services. Mental Handicap Research 7, 97-117.

Sullivan, R. C. (1979). The burn-out syndrome. Journal of Autism and Developmental Disorders, 9, 112-126. doi:10.1007/BF01531298

Tehee, E., Honan, R., \& Hevey, D. (2009). Factors contributing to stress in parents of individuals with autistic spectrum disorders. Journal of Applied Research in Intellectual Disabilities, 22, 34-42. doi:10.1111/j.1468-3148.2008.00437.x

Thompson, D., \& Emira, M. (2011). "They say every child matters, but they don't": An investigation into parental and carer perceptions of access to leisure facilities and respite care for children and young people with autistic spectrum disorder (ASD) or attention deficit, hyperactivity disorder (ADHD). Disability \& Society, 26, 65-78. doi:10.1080/09687599.2011.529667

Touliatos, J., Perlmutter, B. F., \& Straus, M. A. (1990). Handbook of family measurement techniques. Thousand Oaks, CA: Sage Publications. 
Running Head: RESPITE CARE, MARITAL QUALITY, AND STRESS

Welch, V., Hatton, C., Emerson, E., Robertson, J., Collins, M., Langer, S., \& Wells, E. (2012). Do short break and respite services for families with a disabled child in England make a difference to siblings? A qualitative analysis of sibling and parent responses. Children and Youth Services Review, 34, 451-459.

Zloty, A., Roger, K., \& Lobchuk, M.A. (2011). Model for the development of caregiver networks. Work - A Journal of Prevention Assessment \& Rehabilitation, 40, 51-61. 
Running Head: RESPITE CARE, MARITAL QUALITY, AND STRESS

Table 1

Demographic Characteristics of Children with Autism Spectrum Disorder ( $N=118$ children in 101 families; 42 females and 76 males)

\begin{tabular}{|c|c|c|c|c|c|c|}
\hline & \multicolumn{6}{|c|}{ Diagnosis } \\
\hline & \multicolumn{2}{|c|}{ Autism $(n=88)$} & \multicolumn{2}{|c|}{ Asperger $(n=14)$} & \multicolumn{2}{|c|}{$\begin{array}{c}\text { Pervasive } \\
\text { Developmental } \\
\text { Disorder-NOS } \\
(n=16)\end{array}$} \\
\hline & Male & Female & Male & Female & Male & Female \\
\hline \multicolumn{7}{|c|}{ Birth order of child with ASD } \\
\hline $1^{\mathrm{st}}$ & 28 & 17 & 5 & 3 & 7 & 3 \\
\hline $2^{\text {nd }}$ & 22 & 7 & 2 & 2 & 1 & 2 \\
\hline $3^{\text {rd }}$ & 6 & 4 & 1 & 1 & 1 & 2 \\
\hline $6^{\text {th }}$ & 3 & 1 & 0 & 0 & 0 & 0 \\
\hline Gender & 59 & 29 & 8 & 6 & 9 & 7 \\
\hline Age $\quad$ Mean & 7.92 & 8.39 & 10.73 & 10.97 & 7.28 & 7.67 \\
\hline$(S D)$ & $(3.41)$ & $(4.82)$ & $(3.01)$ & $(2.75)$ & (3.03) & (3.39) \\
\hline \% Receiving respite & $61.0 \%$ & $62.1 \%$ & $37.5 \%$ & $83.3 \%$ & $88.9 \%$ & $71.4 \%$ \\
\hline \multicolumn{7}{|l|}{ Type of respite } \\
\hline Grandparents & 7 & 6 & 0 & 4 & 1 & 3 \\
\hline Extended family & 8 & 2 & 2 & 0 & 0 & 0 \\
\hline Babysitter & 9 & 6 & 1 & 0 & 4 & 0 \\
\hline Community agency & 8 & 3 & 0 & 0 & 3 & 2 \\
\hline Combination & 4 & 1 & 0 & 1 & 0 & 0 \\
\hline
\end{tabular}


Running Head: RESPITE CARE, MARITAL QUALITY, AND STRESS

Table 2

Means, Standard Deviations, and Correlations for All Measured Variables

\begin{tabular}{|c|c|c|c|c|c|c|c|c|c|c|c|c|}
\hline & 1 & 2 & 3 & 4 & 5 & 6 & 7 & 8 & 9 & 10 & 11 & 12 \\
\hline 1.WRespite Hrs. & 1.0 & & & & & & & & & & & \\
\hline 2.HRespite Hrs. & $.99 * * *$ & 1.0 & & & & & & & & & & \\
\hline 3.WStress Severity & $-.34 * * *$ & $-.35 * * *$ & 1.0 & & & & & & & & & \\
\hline 4.WStress Frequency & $-.25 * * *$ & $-.28 * * *$ & $.83 * * *$ & 1.0 & & & & & & & & \\
\hline 5.HStress Severity & $-.26 * * *$ & $-.27 * * *$ & $.74 * * *$ & $.62 * * *$ & 1.0 & & & & & & & \\
\hline 6.HStress Frequency & $-.25 * * *$ & $-.26 * * *$ & $.50 * * *$ & $.59 * * *$ & $.76 * * *$ & 1.0 & & & & & & \\
\hline 7.WRDAS & $.39 * * *$ & $.32 * * *$ & $-.68 * * *$ & $-.49 * * *$ & $-.60 * * *$ & $-.41 * * *$ & 1.0 & & & & & \\
\hline 8.WAnx Attachment & $-.35 * * *$ & $-.33 * * *$ & $.58 * * *$ & $.40 * * *$ & $.52 * * *$ & $.41 * * *$ & $-.73 * * *$ & 1.0 & & & & \\
\hline 9.WAvoid Attachment & $-.39 * * *$ & $-.40 * * *$ & $.52 * * *$ & $.41 * * *$ & $.53 * * *$ & $.43 * * *$ & $-.62 * * *$ & $.72 * * *$ & 1.0 & & & \\
\hline 10.HRDAS & $.42 * * *$ & $.39 * * *$ & $-.59 * * *$ & $-.40 * * *$ & $-.66 * * *$ & $-.47 * * *$ & $.78 * * *$ & $-.63 * * *$ & $-.69 * * *$ & 1.0 & & \\
\hline 11.HAnx Attachment & $-.39 * * *$ & $-.29 * * *$ & $.44 * * *$ & $.27 * * *$ & $.51 * * *$ & $.40 * * *$ & $-.67 * * *$ &.$-.76 * * *$ & $.67 * * *$ & $-.77^{* * *}$ & 1.0 & \\
\hline 12. HAvoid Attachment & $-.30 * * *$ & $-.30 * * *$ & $.47 * * *$ & $.32 * * *$ & $.53 * * *$ & $.42 * * *$ & $-.74 * * *$ & $.56 * * *$ & $.74 * * *$ & $-.81 * * *$ & $.79 * * *$ & 1.0 \\
\hline 13.WUplifts Intensity & $.25 * * *$ & $.23 * *$ & $-.23 * *$ & -.10 & $-.30 * * *$ & $-.25 * *$ & $.44 * * *$ & $-.32 * * *$ & $-.43 * * *$ & $.45 * * *$ & $-.38 * * *$ & $-.47 * * *$ \\
\hline 14.WUplifts Frequency & $.21 * *$ & $.24 * *$ & $-.28 * * *$ & .01 & $-.34 * * *$ & -.14 & $.47 * * *$ & $-.35 * * *$ & $-.42 * * *$ & $.44^{* * *}$ & $-.39 * * *$ & $-.46 * * *$ \\
\hline 15.HUplifts Intensity & $.30 * * *$ & $.29 * * *$ & $-.26 * * *$ & $-.23 * *$ & $-.39 * * *$ & $-.29 * * *$ & $.45 * * *$ & $-.36 * * *$ & $-.44 * * *$ & $.53 * * *$ & $-.40 * * *$ & $-.47 * * *$ \\
\hline 16. HUplifts Frequency & $.33 * * *$ & $.32 * * *$ & $-.26 * * *$ & -.14 & $-.37 * * *$ & $-.16^{*}$ & $.48^{* * *}$ & $-.37 * * *$ & $-.41 * * *$ & $.46 * * *$ & $-.41 * * *$ & $-.51 * * *$ \\
\hline$M$ & 6.59 & 6.32 & 107.09 & 31.40 & 108.98 & 31.28 & 58.87 & 47.61 & 51.27 & 58.45 & 51.34 & 51.57 \\
\hline S.D. & 9.54 & 9.18 & 28.84 & 9.94 & 31.26 & 11.51 & 12.69 & 26.19 & 28.05 & 12.73 & 28.40 & 26.08 \\
\hline
\end{tabular}

\begin{tabular}{cllll}
\hline & 13 & 14 & 15 & 16 \\
\hline 13.WUplifts Intensity & 1.0 & & & \\
14.WUplifts Frequency & $.88^{* * *}$ & 1.0 & & \\
15.HUplifts Intensity & $.65^{* * *}$ & $.60^{* * *}$ & 1.0 & \\
16.HUplifts Frequency & $.55^{* * *}$ & $.54^{* * *}$ & $.70^{* * *}$ & 1.0 \\
\hline$M$ & 102.64 & 28.51 & 101.91 & 29.69 \\
S.D. & 24.18 & 9.78 & 27.95 & 14.29 \\
\hline
\end{tabular}

$$
* p<.05, * * p<.01, * * * p<.001
$$




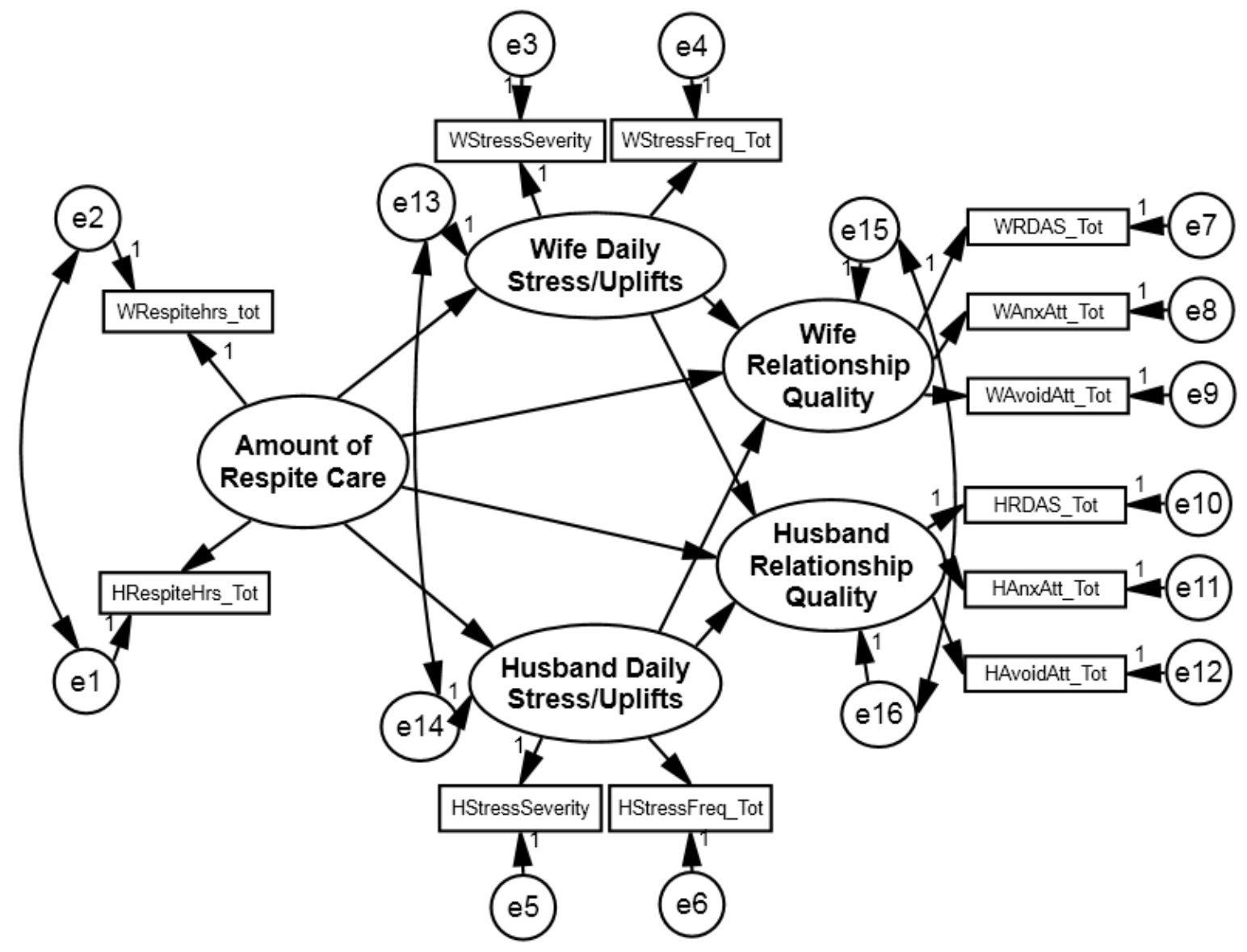

Figure 1. Measurement and actor partner independence structural equation model with number of hours of respite care predicting husband and wife relationship quality with husband and wife stress or uplifts as potential mediating variables.

Note. Husband and wife age, education, income, length of marriage, and number of children were included as control variables in the model. 


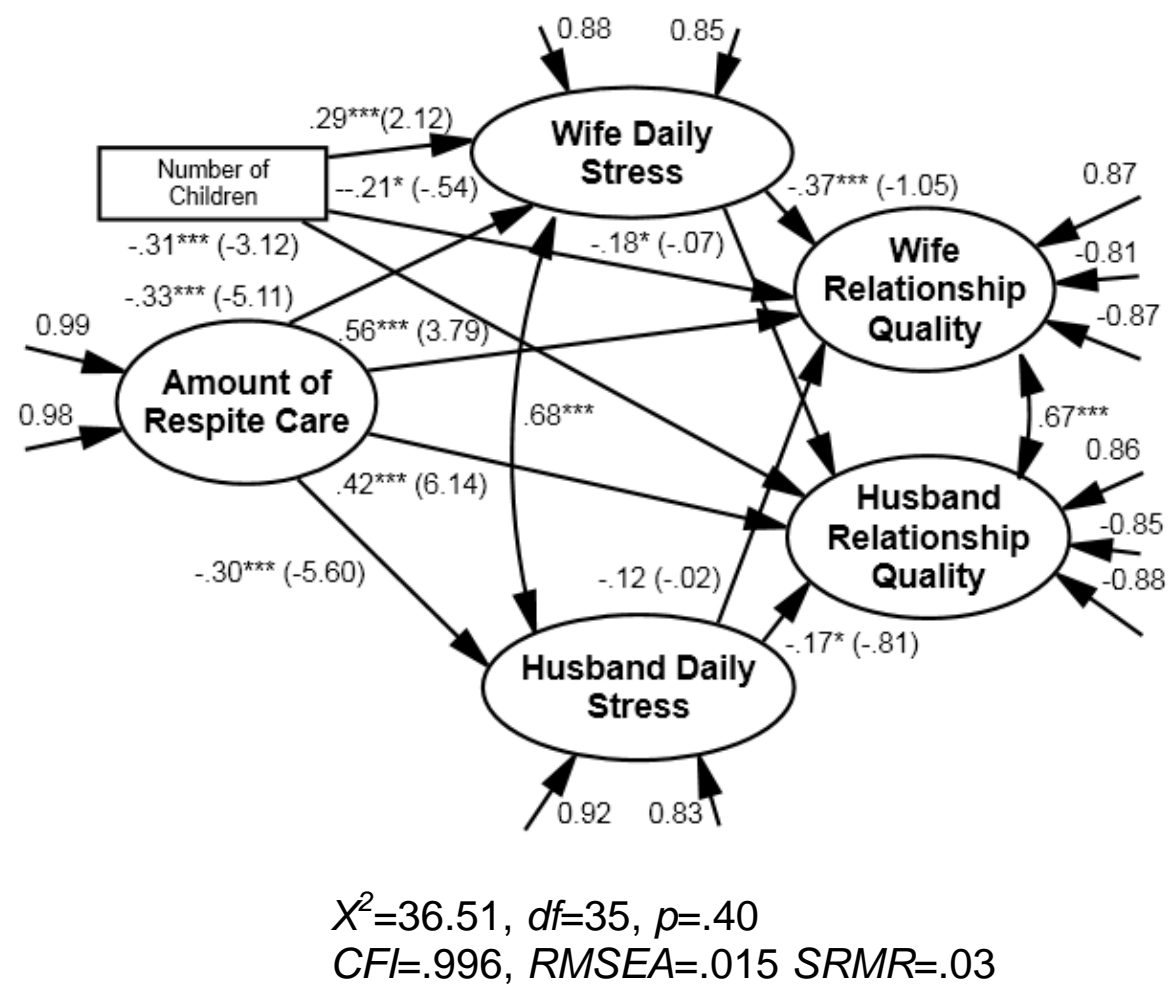

Figure 2. SEM results with standardized betas (unstandardized in parentheses) for number of hours of respite care predicting husband and wife relationship quality with husband and wife stress as mediating variables.

Note. Most control variables (husband and wife age, education, income, hours of employment, and length of marriage) were not related to the outcome variables, so those paths are not included.

${ }^{*} \mathrm{p}<.05,{ }^{* *} \mathrm{p}<.01,{ }^{* * *} \mathrm{p}<.001$ 


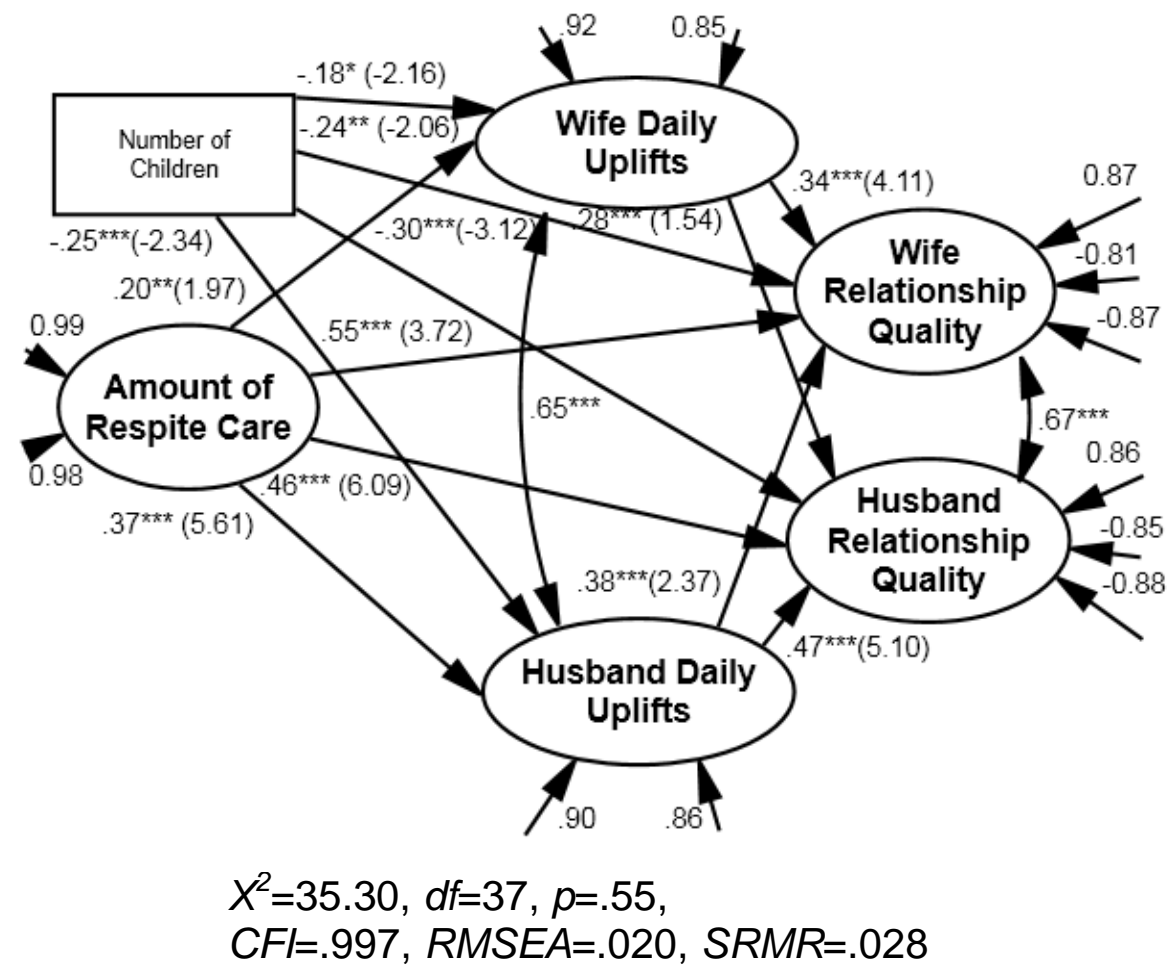

Figure 3. SEM results with standardized betas (unstandardized in parentheses) for number of hours of respite care predicting wife and husband relationship quality with husband and wife uplifts as potential mediating variables.

Note. Most control variables (husband and wife age, education, income, hours of employment, and length of marriage) were not related to the outcome variables, so those paths are not included.

${ }^{*} \mathrm{p}<.05,{ }^{* *} \mathrm{p}<.01,{ }^{* * *} \mathrm{p}<.001$ 
Running Head: RESPITE CARE, MARITAL QUALITY, AND STRESS

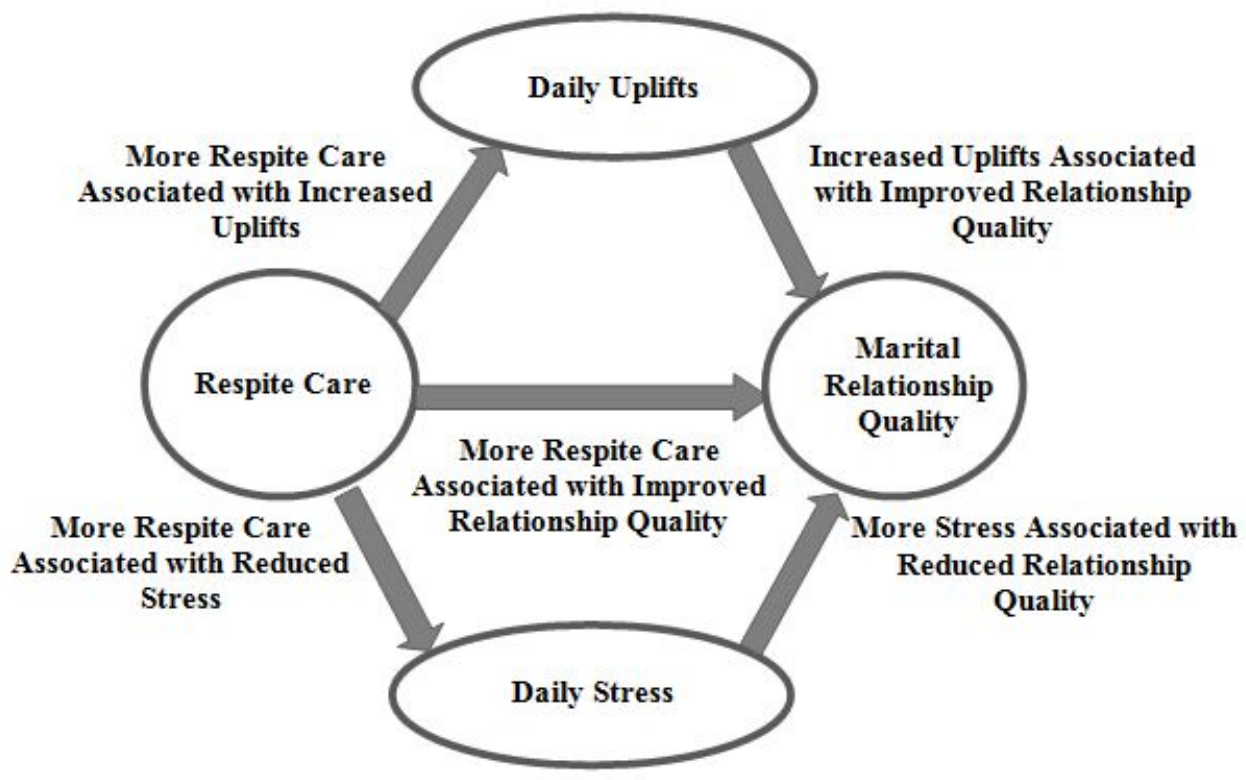

Figure 4. General model of SEM findings documenting statistically significant associations between respite care, stresses and uplifts, and marriage relationship quality for both husbands and wives. 